\title{
OPTIMAL UTILIZATION OF ELECTRICAL ENERGY FROM POWER PLANTS BASED ON FINAL ENERGY CONSUMPTION USING GRAVITATIONAL SEARCH ALGORITHM
}

Purpose. Energy consumption is a standard measure to evaluate the progress and quality of life in a country. When used properly and logically it could be cause of progress in science, technology and welfare of the people in any country and otherwise irreparable economic losses and economic gross recession would happen. And finally, the quantity of energy consumption per GDP will increase day by day. Electrical energy, as the most prominent type of energy, is very important. In this article based on a different approach, according to the final consumption of electric energy, a proper economic planning in order to supply electrical energy is submitted. In this programming, the details of final energy consumption, will replace with the information of power network, by considering the network efficiency and power plants. Operation of power plants is based on the energy optimization entranced to a plant. By using the proposed method and gravitational search algorithm, the total cost of electrical energy can be minimized. The results of simulation and numerical studies show better convergence of gravitational search algorithm in comparison with other existing methods in this area. References 17, tables 2, figures 4.

Key words: gravitational search algorithm, energy, electrical energy, economic distribution, final energy consumption.

Цель. Энергопотребление является стандартной мерой для оценки прогресса и качества энизни в стране. Правильное и обоснованное ее использование может привести к прогрессу в науке, технике и благосостоянии людей в любой стране, в противном случае произойдут непоправимые экономические потери и падение валового внутреннего продукта. И, наконец, количество потребленной энергии на единицу ВВП будет возрастать с каждым днем. Электрическая энергия, как основной вид энергии, является весьма важной. В данной статье, основываясь на различных подходах, в соответствии с конечным потреблением электрической энергии, представлено соответствующее экономическое планирование подачи электроэнергии. При этом, подробности конечного потребления энергии заменяются информацией о сети электроснабжения, учитывая эффективность сети и электростанций. Работа электростанций основана на оптимизации энергии, производимой ею. Используя предложенный метод и алгоритм гравитационного поиска, можно минимизировать общую стоимость электрической энергии. Результаты моделирования и численных исследований показывают лучиую сходимость алгоритма гравитационного поиска по сравнению с другими существующими методами в данной области. Библ. 17, табл. 2, рис. 4.

Ключевые слова: алгоритм гравитационного поиска, энергия, электрическая энергия, экономическое распределение, конечное потребление энергии.

Introduction. The energy consumption trend in recent years has been very rapid and worrying. This process in developing countries, especially Iran has been much higher than the global average. The continuation of energy supply and ensuring long-term access to resources, needs a comprehensive energy plan, and therefore the energy planning is the undeniable necessities of economic, national and strategic in a country. One of the key topics that is discussed in the context of energy planning, is the economic distribution of electrical energy.

Economic dispatch problem using Tucker-Cohen is performing well and appropriate economic status is determined. When these conditions are met, all the plants that are in circuit, with the exception of plants that can effectively inject their maximum power into the network, due to their amount of fuel are loaded [1]. Economic dispatch methods can be placed in two groups of analytical methods and intelligent systems. One of the most famous and oldest analytical methods, is Lagrange method [2]. Including the intelligent systems, can note the optimization of the application of innovative methods in economic dispatch and entrance of plant into the circuit [3].

Despite the research conducted on the economic dispatch and as a result, the problem of entrancing the plant into the circuit, most of these studies has been appropriated by electric power consumer's expectations. In this paper a different approach with regard to the undeniable importance of energy, is presented in the field of economic distribution with needs of consumers. In describing this new and different expression, according to the final consumption of electric energy, economic distribution of this energy consumption will be established by power plants. And then based on different power plants efficiency, input energy requirements of power plants, is planned and optimized.

In this paper, first in the second part, definition and discussion of how to formulate economic distribution of energy is expressed. Then, in the third part gravitational search algorithm is presented. The fourth part of the article is devoted to the application of gravitational search algorithm in the context of economic distribution. In the fifth part the simulation results are given and finally in the sixth part of the article summary is expressed.

Problem statement and formulation. The cost of electrical power distribution for the whole system is equal to the sum of Costs of different units [4]. The basic operation of the system is that the total output powers must be equal to the total load [5]. In this case the economic dispatch is expressed by relations:

$$
\begin{gathered}
F_{T}=\sum_{i=1}^{N} F_{i}\left(P_{i}\right) ; \\
\varnothing=0=P_{R}-\sum_{i=1}^{N} P_{i},
\end{gathered}
$$


where $F_{T}$ is the total cost of the operation from the system, $N$ is the number of power plants, $P_{i}$ is the share of $i$-th power plant from the total demand, and $F_{i}\left(P_{i}\right)$, is the cost of power plants, in order to generating power $P$. $\varnothing$ indicating the fundamental issue $P_{R}$, is the total demand.

It should be noted that each plant is able to operate in the range of its unique ability to inject power. This range of capability is expressed as:

$$
P_{i . \min } \leq P_{i} \leq P_{i . \max }
$$

where $P_{i \text { min }}$ and $P_{i \text { max }}$ respectively, are the minimum and maximum power injection at the $i$-th power plant.

Expressions (1) and (2) show the overview of the economic distribution of electric power, we intend to extend this relation into the energy definition domain. So, in the new expression, $E_{R}$ replacing with $P_{R}$ and we define total electric energy demand based on final consumption of electrical energy. Therefore, this new attitude we try to provide electrical energy demand in a way to reduce the rate of its costs. The subject that expressed in fact is an optimization problem with a constraint which can be solved with optimization existing methods. However analytical methods such as Lagrange method solve this issue, but in the complex systems and real great, especially when considering the losses and efficiency of the network and in fact nonlinear problem, becomes more with computational complexity. In these situations, evolutionary optimization algorithms, represent their ability to well solve such issues. Various evolutionary optimization algorithms have been proposed and introduced by various authors [6-10].

Gravitational search algorithm. Considering the extent and complexity of the issues and the importance of speed to get answers, other classical optimization methods, do not have ability to solve many issues, and instead of searching of comprehensive space, random search algorithms are used to define the problem. This has led to the use of heuristic search algorithm (intuitive or initiatives) which have grown substantially in recent years [6-10]. Heuristic algorithms have demonstrated their high ability in many fields of science such as transport [11], bioinformatics [12], data mining [13], physical chemistry [14], electronics [15] and other related fields. The achievement of an appropriate mathematical model to the process of searching for innovative methods, is very hard and even impossible [13]. Therefore, this type of algorithms, can be named as «black boxes» optimization algorithms [16].

According to the gravity law each mass perceived location and status of other masses through the law of gravitational attraction. Therefore, this force can be used as a tool for information exchange. The optimum detector designed to solve the optimization problem can be used, which each answer can be defined as a position in space and its similarity to the other solutions can be expressed as a distance. The rate of masses is determined according to the objective function [17].

However, imagine the system as a set of $m$ object. The position of each object is a point in space which is an answer of the problem. In (4), the position of dimension $d$ of the object $i$ is shown with $x_{i}^{d}$

$$
X_{i}\left(x_{i}^{1}, \ldots, x_{i}^{d}, \ldots, x_{i}^{n}\right) .
$$

At first, randomly the initial position of the objects, is define in the space of problem definition, these objects due to the forces which exert to each other proceed towards the answer of the problem.

In this system at time $t$ to mass $i$ from mass $j$ in the direction of dimension $d$ force equal to $F_{i j}^{d}(t)$ is imported. $M_{g j}$ is gravitational mass of mass $j, G(t)$ is the gravitational constant in time $\mathrm{t}$ and $R_{i j}$ is the distance between the two objects $j$ and $i$. Euclidean distance is used to determine the distance between the objects. $\varepsilon$ is a very small number

$$
\begin{gathered}
F_{i j}^{d}(t)=\frac{G(t) M_{g j}(t)}{R_{i j}(t)+\varepsilon}\left(x_{j}^{d}(t)-x_{i}^{d}(t)\right) ; \\
R_{i j}(t)=\left\|X_{i}(t) \cdot X_{j}(t)\right\|_{2} .
\end{gathered}
$$

Force on object $j$ in the direction of dimension $d$ at the time $t, F_{i}^{d}(t)$, is calculated according to (7). In this equation, $r_{1}$ is a random number with uniform distribution in [0-1]

$$
F_{i}^{d}(t)=\sum_{j=1, j \neq i}^{m} r_{1} F_{i j}^{d}(t) .
$$

Acceleration of object $i$ in the direction of dimension $d$ at time $t$ is shown with $a_{i}^{d}(t)$ and inertial mass of object $i$ is shown with $M i_{1}(t)$

$$
a_{i}^{d}(t)=\frac{F_{i}^{d}(t)}{M i_{1}(t)} .
$$

In this case we have:

$$
\begin{aligned}
& V_{i}^{d}(t+1)=r_{2} V_{i}^{d}(t)+a_{i}^{d}(t) ; \\
& x_{i}^{d}(t+1)=x_{i}^{d}(t)+V_{i}^{d}(t+1),
\end{aligned}
$$

where $r_{1}$ and $r_{2}$ are uniformly-distributed random numbers in [0-1] which have been used to maintain the random search. $V_{i}^{d}$ is speed of dimension $d$ from object $i$.

Relationship (5) to (10), will repeat until the convergence condition is established.

Problem solving of economic distribution using gravitational search algorithm. Distribution of electrical energy, is a non-linear problem and due to high provisions has a very high complexity. For this reason, the usual methods for solving this problem are faced with many problems, and either are not able to solve this problem or solve the problem with many hardships. For these reasons described in this article gravitational search algorithm is used to solve nonlinear problems which is very efficient.

Electric energy demand is equal to $E_{R}$. In the period studied, power plants which are available assumed to be constant, so each of these power plants, are at their least production. Different power plants according to the structure have different efficiencies. When the economic distribution of electrical energy is concerned, this fully shows. Thus, only the desired power generation is not considered, but the total final consumption of energy that needed to provide electric energy is optimized. In other words, for effective optimization is done. 
We introduce the network efficiency with $\eta$ and efficiency of different power plants with $\eta_{i}$ for $n, i=1,2, \ldots$

$$
\begin{gathered}
E_{R L}=\eta E_{R} ; \\
E_{R L}=\sum_{i=1}^{n} \eta_{i} E_{i},
\end{gathered}
$$

where $E_{R L}$ is the energy demand of the power plant due to final energy consumption and efficiency of the network and $E_{i}$ is the input energy required to $i$-th power plant.

The simulation is done in time domain, so, the mean power and electric power, are the same.

Simulations and results. The simulation is performed based on a specific system in accordance with Table 1. Values of $a, b$ and $c$ related to the input data of costs of power plant operation that is used to calculate the relation

$$
F_{i}\left(P_{i}\right)=a P_{i}^{2}+b P_{i}+c,
$$

where $F_{i}$ is the operating costs, and $P_{i}$ is the amount of $i$-th power plant output power.

Information about power system plants

\begin{tabular}{|c|c|c|c|c|c|c|}
\hline unit & $P_{\min }(\mathrm{MW})$ & $P_{\max }(\mathrm{MW})$ & $a$ & $b$ & $c$ & $\eta$ \\
\hline 1 & 150 & 455 & 0.00048 & 19.16 & 1000 & 30 \\
\hline 2 & 150 & 455 & 0.00031 & 26.17 & 970 & 45 \\
\hline 3 & 20 & 130 & 0.002 & 16.6 & 700 & 32 \\
\hline 4 & 20 & 130 & 0.00211 & 16.5 & 680 & 35 \\
\hline 5 & 25 & 162 & 0.00398 & 19.7 & 450 & 28 \\
\hline 6 & 20 & 80 & 0.007 & 22.26 & 370 & 27 \\
\hline 7 & 25 & 85 & 0.00079 & 27.74 & 480 & 30 \\
\hline 8 & 10 & 55 & 0.004 & 25.92 & 660 & 35 \\
\hline 9 & 10 & 55 & 0.00222 & 27.27 & 665 & 33 \\
\hline 10 & 10 & 55 & 0.002 & 27.79 & 670 & 33 \\
\hline
\end{tabular}

It assumed that $E_{R}$ is equal to $1500 \mathrm{kWh}$, if the efficiency of the network is equal to $75 \%$, so the demand from the power plant $E_{R L}$ will be $2000 \mathrm{kWh}$. Performance of the gravity algorithm, was compared with genetic algorithm and particle population algorithm, the results of the implementation of the three algorithms are shown in Table 2.

The simulation results of the studied power system

\begin{tabular}{|l|c|c|c|}
\hline & GA & PSO & GSA \\
\hline The best answer & 70492.205 & 70526.659 & 70785.216 \\
\hline Average of answers & 70546.156 & 70574.379 & 70837.164 \\
\hline The worst answer & 70913.142 & 71052.215 & 71356.184 \\
\hline
\end{tabular}

To evaluate the proposed method, gravitational algorithm, genetic algorithm and particle swarm algorithm in solving the problem of finding the minimum of economic distribution problem, have been implemented under the same conditions. For $n=30$, and population size equal to 50 , the results for 1500 times iteration is given in Table 2. And for comparison, the fitness average and the best answer which so far has been observed are calculated. These parameters were calculated for 20 times for the implementation of the stand-alone application and middle of the results is obtained. The results of gravitational algorithm show better performance. In the PSO simulation, relation (14) is used for updating the particles velocity in this relation, $c_{1}=c_{2}=2$, and $w$ decreases linearly from 0.9 to 0.2 . In this relation $V_{i}^{d}(t)$, is velocity of particle $i$ in $d$ dimension in time $t$, and $r_{1}$ and $r_{2}$ are random numbers uniformly distributed between zero and one. Also $g_{\text {best }}$ is the best position that has been found by the community, $p_{\text {best } i}$ is the best position that particle $i$ so far has been accessed

$$
\begin{aligned}
& V_{i}^{d}(t+1)=w(t) V_{i}^{d}(t)+c_{1} r_{1 i}(t)\left[p_{\text {best } i}{ }^{d}(t)-V_{i}^{d}(t)\right]+ \\
& +c_{2} r_{2 i}(t)\left[g_{\text {best }}{ }^{d}(t)-X_{i}^{d}(t)\right] .
\end{aligned}
$$

In order to evaluate the results of the presented objective function optimization, this case is shown in the Table 2. As seen in Table 2, gravitational search algorithm has more acceptable performance and results than GA and PSO algorithms. The results demonstrate the convergence of the GSA algorithm compared to RGA and PSO algorithms.

In order to evaluate the progress of the optimization process, in Fig. 1 to Fig. 3 the accomplishing pattern of the optimal solution for gravitational, particle population and genetics algorithms is drawn. Also, in order to have a proper comparison of the performance for these algorithms, the achieving pattern of these algorithms for optimal solution are shown in Fig. 4, simultaneously.



Fig. 1. Accomplishing pattern of the optimal solution by GSA algorithm

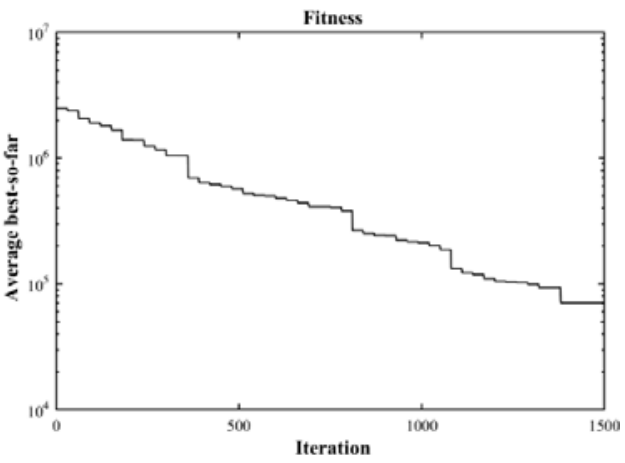

Fig. 2. Accomplishing pattern of the optimal solution by PSO algorithm

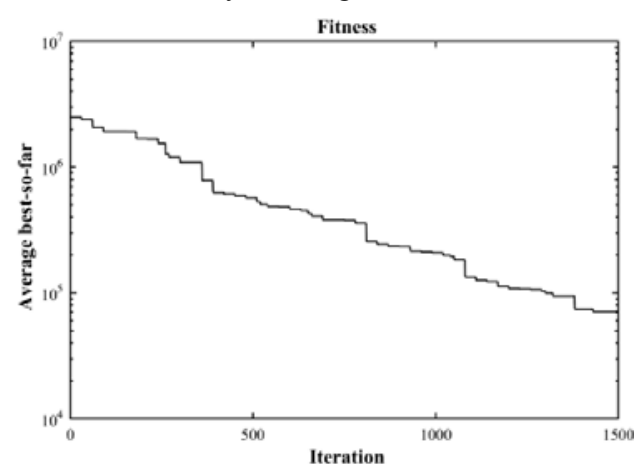

Fig. 3. Accomplishing pattern of the optimal solution by GA algorithm 


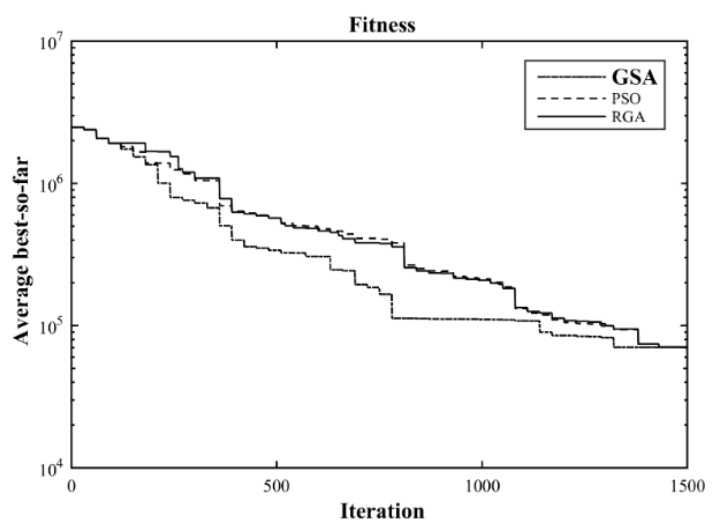

Fig. 4. The comparison of the evolutionary algorithms GSA, PSO and GA to achieve the optimal solution

Conclusion. Electrical energy is very important, and therefore it is important to minimize the energy costs. In a new approach in this paper, according to the final consumption of electric energy and efficiency of power system planets and network, the economic distribution of electrical energy is created. In this regard, according to the non-linear nature of the problem, evolutionary algorithms have been used. The results of the simulation show the well performance of gravity algorithm in compare to other algorithms.

\section{REFERENCES}

1. Kuhn H.W., Tucker A.W. Nonlinear Programming. Proceedings of the Second Berkeley Symposium on Mathematical Statistics and Probability, University of California, 1951, pp. 481-492.

2. Yamin H.Y. Review on methods of generation scheduling in electric power systems. Electric Power Systems Research, 2004, vol.69, no.2-3, pp. 227-248. doi: 10.1016/j.epsr.2003.10.002.

3. Yuan X., Su A., Nie H., Yuan Y., Wang L. Application of enhanced discrete differential evolution approach to unit commitment problem. Energy Conversion and Management, 2009, vol.50, no.9, pp. 2449-2456. doi: 10.1016/j.enconman.2009.05.033.

4. Zaman M.F., Elsayed S.M., Ray T., Sarker R.A Evolutionary Algorithms for Dynamic Economic Dispatch Problems. IEEE Transactions on Power Systems, 2016, vol.31, no.2, pp. 1486-1495. doi: 10.1109/TPWRS.2015.2428714.

5. Surender Reddy S., Bijwe P.R., Abhyankar A.R. Real-Time Economic Dispatch Considering Renewable Power Generation Variability and Uncertainty Over Scheduling Period. IEEE Systems Journal, 2015, vol.9, no.4, pp. 1440-1451. doi: 10.1109/JSYST.2014.2325967.
6. Tang K.S., Man K.F., Kwong S., He Q. Genetic algorithms and their applications. IEEE Signal Processing Magazine, 1996, vol.13, no.6, pp. 22-37. doi: 10.1109/79.543973.

7. Kirkpatrick S., Gelatt C.D., Vecchi M.P. Optimization by Simulated Annealing. Science, 1983, vol.220, no.4598, pp. 671680. doi: 10.1126/science.220.4598.671.

8. Farmer J.D., Packard N.H., Perelson A.S. The immune system, adaptation, and machine learning. Physica D: Nonlinear Phenomena, 1986, vol.22, no. 1-3, pp. 187-204. doi: 10.1016/0167-2789(86)90240-x.

9. Dorigo M., Maniezzo V., Colorni A. Ant system: optimization by a colony of cooperating agents. IEEE Transactions on Systems, Man and Cybernetics, Part B (Cybernetics), 1996, vol.26, no.1, pp. 29-41. doi: 10.1109/3477.484436.

10. Kennedy J., Eberhart R. Particle swarm optimization. Proceedings of ICNN'95 - International Conference on Neural Networks. doi: 10.1109/icnn.1995.488968.

11. Zarandi M.H.F., Hemmati A., Davari S. The multi-depot capacitated location-routing problem with fuzzy travel times. Expert Systems with Applications, 2011, vol.38, no.8, pp. 1007510084. doi: 10.1016/j.eswa.2011.02.006.

12. Mitra S., Banka H. Multi-objective evolutionary biclustering of gene expression data. Pattern Recognition, 2006, vol.39, no.12, pp. 2464-2477. doi: 10.1016/j.patcog.2006.03.003.

13. Zahiri S.H. Swarm Intelligence and Fuzzy Systems. Nova Science Publ., USA, 2010.

14. Darby S., Mortimer-Jones T.V., Johnston R.L., Roberts C. Theoretical study of $\mathrm{Cu}-\mathrm{Au}$ nanoalloy clusters using a genetic algorithm. The Journal of Chemical Physics, 2002, vol.116, no.4, pp. 1536-1550. doi: 10.1063/1.1429658.

15. Coello Coello C.A., Luna E.H., Aguirre A.H. Use of Particle Swarm Optimization to Design Combinational Logic Circuits. Lecture Notes in Computer Science, 2003, pp. 398-409. doi: 10.1007/3-540-36553-2_36.

16. Wolpert D.H., Macready W.G. No free lunch theorems for optimization. IEEE Transactions on Evolutionary Computation, 1997, vol.1, no.1, pp. 67-82. doi: 10.1109/4235.585893.

17. Rashedi E., Nezamabadi-pour H., Saryazdi S. GSA: A Gravitational Search Algorithm. Information Sciences, 2009, vol.179, no.13, pp. 2232-2248. doi: 10.1016/j.ins.2009.03.004.

Received 14.03.2018

\author{
Zeinab Montazeri ${ }^{1}$, Candidate of Power Engineering, \\ M.Sc. Student, \\ Taher Niknam ${ }^{1}$, Doctor of Power Engineering, Professor, \\ ${ }^{1}$ Department of Electrical Engineering, \\ Islamic Azad University of Marvdasht, \\ Marvdasht, I.R. Iran. \\ phones $+989171128689,+989171876173$ \\ e-mail: Z.montazeri2002@gmail.com,niknam@sutech.ac.ir
}

How to cite this article:

Montazeri Z., Niknam T. Optimal utilization of electrical energy from power plants based on final energy consumption using gravitational search algorithm. Electrical engineering \& electromechanics, 2018, no.4, pp. 70-73. doi: 10.20998/2074-272X.2018.4.12. 